\title{
Educação ambiental no contexto da educação básica
}

Anelize Queiroz Amaral any qa@hotmail.com 0000-0001-9534-572X Docente na Universidade Tecnológica Federal do Paraná - UTFPR - Dois Vizinhos

Maria Andrêsa da Silva andresa.bio.ea@gmail.com 0000-0003-4426-7412 Mestre em Educação - Universidade Estadual Júlio Mesquita Filho - Unesp - Rio Claro

Kassiana da Silva Miguel kassianamiguelunioeste@gmail.com 0000-0003-0565-6343 Doutoranda do Curso de Pósgraduação em Educação em Ciências e Matemática pela Universidade Estadual do Oeste do Paraná UNIOESTE

Daniela Macedo de Lima danielamlima@utfpr.edu.br 0000-0002-8018-3163

Prof. Dra. em Agronomia - Produção Vegetal, Coordenação de Ciências Biológicas, UTFPR - Dois Vizinhos

Taís Regina Cutchma tais.cutchma@hotmail.com 0000-0003-4887-033 Mestranda do curso de Biotecnologia pela Universidade Tecnológica Federal do Paraná - Dois Vizinhos

\section{RESUMO}

Os problemas ambientais ocasionados no ambiente pelas diversas ações humanas somados à falta de conhecimento sobre a temática ambiental e os processos educativos vêm sendo objeto de diversas discussões desde os anos de 1960 e 1970. Com suas origens em lutas e conquistas de movimentos ambientalistas, fora dos âmbitos educacionais, essa discussão avançou de maneira fragilizada no que diz respeito às questões teórico-metodológicas, podendo ser observadas limitações no que diz respeito a propostas de Educação Ambiental (EA) em uma perspectiva crítica. Neste contexto, em que tais limitações são observadas, se faz necessário que a EA seja abordada numa ótica que busque romper com práticas reducionistas, pontuais e pragmáticas. Não podemos nos tornar reféns de ações que objetivam somente separar resíduos, plantar árvores e economizar recursos. Precisamos avançar em discussões que levem até os nossos alunos a compreensão de uma EA crítica que questiona o atual modelo de relação sociedade-natureza. Diante disso, este trabalho objetivou investigar o conhecimento conceitual sobre EA de 22 alunos do sexto ano do Ensino Fundamental, de um Colégio Estadual do município de Dois Vizinhos, Sudoeste do Estado do Paraná, por meio da aplicação de questionários e a realização de vivências socioambientais em uma trilha ecológica do município. Para tanto, foram realizadas perguntas sobre conceitos relacionados à EA e, posteriormente, realizou-se práticas na trilha ecológica Jirau Alto, que fica nas proximidades do colégio. Em seguida, esses dados foram analisados e observou-se uma visão conservacionista e pragmática de EA pela maioria dos estudantes (13), que posteriormente foram trabalhadas por meio de oficinas desenvolvidas pelos licenciandos do Programa de Bolsas de Iniciação à Docência PIBID/BIOLOGIA e do Grupo de Pesquisas de Educação Ambiental - GPEEA/UTFPR do Câmpus de Dois Vizinhos, Paraná.

PALAVRAS-CHAVE: Educação ambiental. Educação básica. Processos educativos. 


\section{INTRODUÇÃO}

Desde o seu surgimento na Terra o homem vem se apropriando da natureza em busca de sua sobrevivência, resultando no decorrer dos anos, em ações predatórias. Essas ações nos colocam em uma situação, na qual os bens naturais estão se tornando cada vez mais escassos, o que gera conflitos socioambientais relacionados à questões de ordem ambiental, ética, cultural, social, política e econômica. É em meio a esse cenário que o debate ambiental aparece com a possibilidade de promover discussões sobre diferentes temas, que emergem diante desses conflitos.

A temática ambiental é objeto de discussões no âmbito nacional e internacional desde as décadas de 1960 e 1970, apesar das diversas ações humanas já serem sentidas muito antes desse período. Teve seu cerne em manifestações de movimentos ambientalistas, que reconheciam a urgência dos problemas ocasionados no/ao ambiente de um crescimento que estava deixando rastros de destruição nunca antes observados na história da humanidade.

Nesse período, foram propostas uma série de conferências e encontros, além da produção de diversos documentos, que marcaram o início dos debates para se discutir possíveis caminhos para tais problemas que de acordo com Leff (2009) retratam uma crise do conhecimento/civilizatória.

Para o autor supracitado, a problemática ambiental emerge nos tempos modernos e na transição para a pós-modernidade, como uma crise civilizatória. Esta "é essencialmente, uma crise do conhecimento, das formas como compreendemos o mundo e intervimos na natureza" (LEFF, 2009, p. 213).

Frente à degradação ambiental, cada vez mais em evidência na sociedade, fica claro que os problemas socioambientais gerados por essa relação problemática não surgiram na contemporaneidade, mas tornaram-se ainda mais acentuados, culminando em uma situação em que o próprio planeta Terra passou a ser um objeto à disposição do homem, em uma visão antropocêntrica (AMARAL, 2018).

As máquinas se colocaram como uma extensão do corpo do homem, o que, aparentemente, deveria ser algo extraordinário, pois multiplica a produção humana com menor esforço físico e tempo cronológico; por outro lado, Ihe roubou a identidade de uma tradição e mantêm, até os dias de hoje, a riqueza nas mãos de poucos. Além do que, esse caminho construído, no qual a natureza torna-se presente como recurso para o ser humano, compromete as condições de sobrevivência das espécies e, entre elas, está a nossa (BORNHEIM, 2001).

Foi diante desse cenário que, na década de 1990, somado a abertura para que outros setores da sociedade desenvolvessem a EA, surgiram diferentes atores/setores da sociedade com o desejo de participar dessas discussões. Nesse caso, alguns setores com ávidos desejos, passaram a "germinar" em propostas de EA "verdes" com enfoque em ações utilitaristas, pontuais e pragmáticas em detrimento de uma perspectiva crítica que questiona o atual modelo de relação sociedade-naatureza.

Para Brugger (2004), segundo a ótica do conservacionismo a problemática ambiental passou a ser vista, exclusivamente, por suas dimensões naturais e técnicas, negligenciando-se as dimensões sociais e políticas, até mesmo porque se tratava de um período em que essas dimensões eram silenciadas, à época da 
ditadura militar. Brugger (2004, p.83) denominou como "adestramento ambiental" essa tendência conservacionista, caracterizada pela falta de diálogo e por assumir uma perspectiva reducionista, fragmentada e individualista. Essa autora sinalizou o descontentamento com a prevalência do comportamentalismo, que promove a domesticação do sujeito e o impede de apresentar questões incômodas. A saber:

[...] um exemplo notório é o das campanhas do tipo "Plante uma árvore no dia da árvore", ou no Dia da Terra, ou no dia Mundial do Meio Ambiente, ou ainda em qualquer outra dessas atualmente numerosas "datas ecológicas". Mas além do plante uma árvore, quase nada mais é feito, ou seja, as causas do desmatamento são raramente questionadas e o que é pior: às vezes os desmatamentos são atribuídos ao "progresso" e seu preço! Mas o que é progresso não se discute, principalmente como ele se produz e quem o impulsiona (BRUGGER, 2004, p.36, grifos da autora).

Nesse exemplo, mencionado por Brugger (2004) a preocupação e a intencionalidade das práticas voltadas para a conservação e preservação da natureza são centrais. Assim, a ênfase ressaltada pela autora supracitada, atribuída às mudanças de comportamento individual dos sujeitos e à falta de questionamento acerca do atual modelo de relação sociedade-natureza, só expressa uma necessidade de adaptação à forma de organização vigente na sociedade, causando o esvaziamento de reflexões críticas sobre a nossa realidade social e, consequentemente, ambiental. Trata-se, assim, de uma simplificação demasiada no que diz respeito à compreensão do atual modelo de relação sociedade-natureza e da problemática ambiental nele instaurada.

Tal reducionismo referente à questão ambiental prioriza no discurso de seus interlocutores uma perspectiva conservadora, que viabiliza a perpetuação de uma estrutura social que não questiona o atual modelo de relação sociedade-natureza que degrada nossos bens naturais e não questiona as desigualdades sociais (AMARAL, 2018).

Contudo, a visibilidade da questão ambiental tem provocado debates que buscam compreender e encontrar respostas compatíveis com a amplitude dessa questão. Ademais, tem contribuído para a expressão de uma série de reflexões que colocam em pauta diversos questionamentos acerca do atual modelo de relação sociedade-natureza.

Segundo Carvalho (2012) a EA surge da preocupação da sociedade com o futuro da vida e com a qualidade da existência das presentes e futuras gerações. Por este motivo, não restam dúvidas de que os padrões de produção e consumo vêm gerando grandes impactos ambientais e sociais, que podem comprometer o futuro do nosso Planeta.

Nesse sentido, a Educação se coloca como um meio que propicia, de maneira única, o envolvimento da coletividade, devendo ser considerada uma atividade social intencionalizada, que promove a relação com o outro, revelando modos de convivência entre si e com o meio, o que, de acordo com Santana (2005), faz desta uma atividade política necessária.

A respeito dessa dimensão política, Carvalho (2006) explicita que: 
compromissada. Assim, quando entendida como processo indissociável de outros processos de sociabilidade, isto é, como prática social, entre outras, a dimensão política da educação evidencia-se (CARVALHO, 2006, p. 23).

Essa dimensão política da Educação torna-se central no processo educativo, uma vez que, promove a formação de cidadãos participativos, capazes de se posicionarem e fazerem suas escolhas.

A EA, quando compreendida nesse processo de formação como ato político, evita o risco de uma formação para o civismo, no qual muitos ambientalistas e educadores acabam esbarrando suas práticas. Além disso, engloba as dimensões dos conhecimentos, valorativas (éticas e estéticas) e de participação política como proposto por Carvalho (1989; 1994; 2000; 2005; 2006).

Dessa forma, deve-se buscar superar as atividades consideradas de EA que apresentam esvaziamento teórico-metodológico, pois, além de serem descontextualizadas e improvisadas, permanecem, muitas vezes, no senso comum. De acordo com Carvalho (2006, p. 23), "muitas vezes, é na ânsia de que mudanças imediatas sejam implementadas que nos leva de forma aligeirada às interrogações e proposições preponderantemente de ordem prática".

Nesse contexto, a EA se refere à um processo educativo que, além de lidar com concepções e reflexões específicas e relevantes do campo ambiental, não se restringe a simples oferta dessas informações. Ela trabalha de modo amplo com conhecimentos, valores e ações por um posicionamento de ordem política. Por este motivo, é relevante que se repense a maneira pela qual estão sendo realizadas propostas e práticas de EA no contexto escolar.

Diante do exposto, o presente trabalho objetivou investigar os conhecimentos conceituais sobre EA de alunos do 60 ano do Ensino Fundamental. A investigação foi realizada por meio da aplicação de questionários e a realização de vivências socioambientais em uma trilha ecológica, por meio da participação dos licenciandos do Programa de Bolsas de Iniciação à Docência - PIBID/BIOLOGIA e do Grupo de Pesquisas de Educação Ambiental - GPEEA/UTFPR do Câmpus de Dois Vizinhos, Paraná.

\section{PROCEDIMENTOS DA PESQUISA}

Para o levantamento de informações a respeito do conhecimento conceitual sobre EA nesta investigação utilizou-se a aplicação de questionários, como instrumento de coleta de dados em uma abordagem de pesquisa qualitativa (LUDKE; ANDRÉ, 1986). Os sujeitos envolvidos foram os 22 alunos do 60 ano, do Ensino Fundamental de um Colégio Estadual do município de Dois Vizinhos, Sudoeste do Estado do Paraná.

A abordagem de pesquisa qualitativa, conforme Denzin e Lincoln (2006, p. 16): 
Assim, tal abordagem de pesquisa pode oportunizar a ampliação da análise dos dados, colocando-os em relação com o contexto (histórico, social, cultural, econômico e ambiental) para compreender uma questão em estudo que não se apresente como uma interpretação imediatista e superficial da realidade sem levar em consideração suas relações (GIBBS, 2009).

Nesse sentido, o que muda é "o modo de perceber o objeto, que deixa de ser o centro" da pesquisa de forma esvaziada de suas relações com o contexto (DEVECHI; TREVISAN, 2010, p. 157).

Para tanto, foram realizadas perguntas sobre conceitos relacionados à EA e, posteriormente, foram feitas práticas numa trilha ecológica que fica nas proximidades do colégio, Jirau Alto. Tais ações foram realizadas no âmbito educacional, por meio da participação dos licenciandos em formação inicial do Curso de Ciências Biológicas, como bolsistas de iniciação à docência, vinculados ao Programa de Bolsas de Iniciação à Docência - PIBID/ Subprojeto de Biologia, juntamente com o Grupo de Pesquisas e Estudos em Educação Ambiental, da Universidade Tecnológica Federal do Paraná, Câmpus Dois Vizinhos (GPEEA/UTFPR-DV).

O presente trabalho envolveu os alunos em diversas práticas de EA realizadas na Trilha do Parque Ecológico Jirau Alto, assim denominado em virtude do Rio Jirau Alto, manancial de abastecimento de água do município de Dois Vizinhos, PR que sofre com diversos problemas relacionados à poluição. No entanto, antes da saída dos alunos para a trilha ecológica, eles foram questionados, em sala de aula, a respeito de suas concepções prévias de temas relacionados à EA. Posteriormente, os mesmos foram levados a refletir sobre essas concepções por meio de oficinas expositivas-dialogadas, buscando a ruptura e (re)construção de visões que se apresentavam reducionistas e ingênuas acerca da temática ambiental e os processos educativos.

Para o desenvolvimento do trabalho, ocorreram as seguintes etapas:

A - Reflexões e discussões teóricas no decorrer das reuniões do Grupo de Pesquisas e Estudos em Educação Ambiental (GPEEA/UTFPR) e PIBID/BIOLOGIA;

B - Construção de oficinas, que contemplaram a pluralidade metodológica nos processos educativos de Educação Ambiental;

C - Construção do instrumento de coleta de dados de maneira participativa;

D - Desenvolvimento das atividades no contexto escolar e na trilha do Parque Ecológico Jirau Alto.

E - Produção de matérias educomunicativas, que promoveram o acesso da comunidade por meios de tecnologias digitais, disponibilizadas no site http://www.webradioagua.org em parceria com a Itaipu Binacional. Tais atividades envolveram conhecimentos, valores e reafirmaram a necessidade de um posicionamento de ordem política e coletiva.

Diversas ações foram desenvolvidas no decorrer da Trilha do Parque Ecológico Jirau Alto, ações que envolveram conteúdos relacionados à diversas questões ambientais, como poluição, assoreamento, eutrofização, preservação de 
nascentes, poluição das águas por resíduos, relações ecológicas, entre outros. Além disso, também foram explorados temas relacionados aos princípios éticos e estéticos, por meio da Carta da Terra numa contação de histórias e posteriormente, foram construídos spots de matérias áudio-visuais, sociabilizadas por meio do Portal da Web Rádio Água em parceria com a Itaipu Binacional.

Assim, esta atividade possibilitou o desenvolvimento com os alunos e a comunidade de diversos motivos para que cada um se posicione como cidadão participante numa ação eminentemente política que está relacionada ao cuidado com o nosso bem comum. A seguir, imagens desse processo educativo (Fig. 1 e 2):

Figura 1 - Na foto coleta de resíduos sólidos no Parque Ecológico Jirau Alto, Dois Vizinhos, PR.

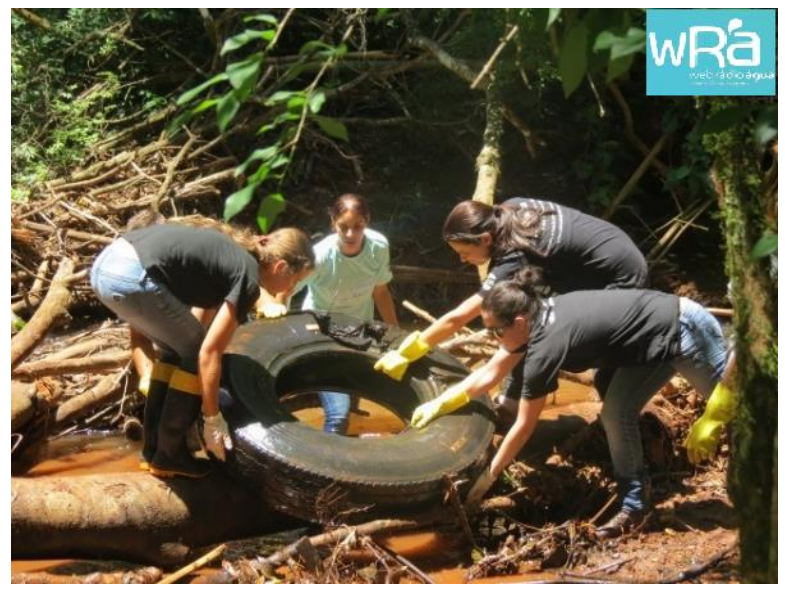

(Fonte: arquivo pessoal)

Figura 2 - Ações de imersão na natureza na trilha ecológica do Parque Ecológico Jirau Alto, Dois Vizinhos, PR.

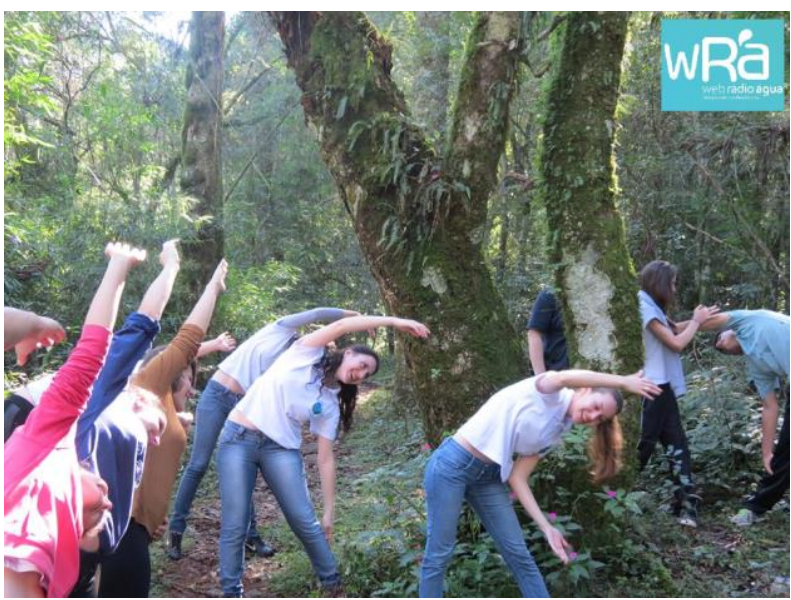

(Fonte: arquivo pessoal)

\section{RESULTADOS E DISCUSSÕES}


Dos 22 alunos participantes desse processo educativo, destes, treze alunos apresentaram a EA como um processo conservacionista. Dados esses que podem ser observados em relatos como esse a seguir:

"Não se pode desmatar. Devemos cuidar das plantas e cuidar dos animais". (Aluno A)

De acordo com Oliveira, Obara e Rodrigues (2007), na maioria das atividades de EA são evidentes os discursos e as preocupações com a preservação dos recursos naturais. Esta postura visa mudar o comportamento do ser humano para proteger a natureza, apesar de haver pouco compromisso acerca das relações históricas, econômicas, políticas e culturais envolvidas na questão ambiental.

Portanto, tal maneira de conceber a EA, está relacionada a uma visão fragmentada de meio, voltando-se, apenas, para o cuidado com o meio natural o belo, deixando de lado uma leitura crítica da problemática ambiental em conexão com as inúmeras mediações sociais, questões econômicas, políticas, e culturais (MININNI-MEDINA, 1997). Essa concepção reafirma a necessidade de se trazer para o âmbito educacional discussões que questionem o atual modelo de relação sociedade-natureza e processos educativos que estão sendo realizados de forma ingênua, pontual e descontextualizada.

Verificou-se, ainda, que sete alunos atribuem às ações de EA um olhar pragmático que incide em práticas reducionistas e utilitaristas, como a prática de separar resíduos sem uma reflexão sobre a questão do consumo e desperdício, por exemplo. Afinal, quando falamos em resíduos, devemos compreender que não basta tirá-los do alcance dos nossos olhos, pois alguém estará sofrendo as consequências de tê-los nas proximidades de sua residência, e, muito provavelmente, seja a classe social menos favorecida.

De acordo com Layargues (2002), a prática educativa que se insere na lógica da metodologia da resolução de problemas ambientais locais de modo pragmático, tornando, por exemplo, a temática da reciclagem do lixo uma atividade-fim, ao invés de considerá-la um tema-gerador para o questionamento das causas e consequências da questão do lixo, remete-nos de forma alienada, à discussão dos aspectos técnicos da reciclagem, evadindo-se da dimensão política e reflexões sobre uma sociedade de consumidores.

Estar inserido em uma sociedade de consumidores é consumir e descartar de forma contínua, para satisfazer necessidade supérfluas e continuar abastecendo o mercado capitalista. Nesse processo, o tempo para desejar um produto e satisfazer o desejo é encurtado, tornando-se menor também a distância entre a satisfação e a lata de lixo (BAUMAN, 2008, p. 111). Assim, esta dinâmica entre desejo, satisfação e desperdício gera grandes quantidades de lixo, criando um problema ambiental e social de grande amplitude.

Assim, segundo Layrargues (2002), a reciclagem tem sido vista de forma ingênua, como resolução do problema do lixo, não questionando o tema gerador do lixo, o consumo desenfreado.

Para tanto, essa questão precisa ganhar em nossas discussões uma visão mais comprometida e crítica sobre aspectos que fogem aos nossos olhares, aspectos que faz dos indivíduos a sua própria mercadoria de forma implacável (BAUMAN, 2008). 
Nessa sociedade mencionada por Bauman (2008), se desvaloriza a durabilidade, o velho passa a ser sinônimo de defasado e para atender todas essas necessidades, impulsos, compulsões e vícios, os indivíduos se baseiam no excesso e desperdício. Nesse ciclo de insatisfação, as crianças de hoje crescem acreditando que consumir e descartar são condições necessárias para a felicidade (BAUMAN, 2008). Assim, crescem pensando que reciclar, reutilizar e reaproveitar são soluções para o fim desse problema.

Em outras palavras, esclareceu-se nessa investigação que, para o exercício desta prática, com certeza, será necessário romper certas atitudes, unindo a EA nas suas diversas dimensões: políticas, econômicas, éticas e culturais (CARNIATTO; VALDAMERI; AMARAL, 2011). Dessa forma, para que a EA desperte no aluno o desejo de trabalhar no sentido de exercer um papel ativo e indispensável na manutenção e/ou melhoria da qualidade do meio ambiente, é fundamental que ele seja instigado a desenvolver seu senso crítico e reflexivo frente ao complexo ambiente do qual ele faz parte.

Em seguida, os alunos foram questionados sobre as práticas ambientais desenvolvidas no contexto escolar. Constatou-se que quatorze alunos acreditavam que o colégio estivesse promovendo ações de EA. No entanto, quando questionados sobre quais seriam essas práticas, não foi possível identificá-las, pois as respostas apresentavam atitudes diárias, que cada cidadão deve ou deveria realizar no seu dia a dia e que não estão vinculadas ao processo educativo, conforme a frase:

"Colocamos o lixo no lixeiro". (Aluno B)

Respostas como essa geraram uma imensa inquietação e preocupação, por se perceber que a EA para muitos alunos ainda se apresenta como uma prática comportamental, que está relacionada, apenas, à separação correta de resíduos e economia de bens naturais totalmente desprovida de uma concepção mais crítica e do entendimento sobre os processos educativos inerentes a essa prática.

De acordo com Brügger (1994), os problemas ambientais e sociais ligados ao lixo têm origem numa mentalidade instrumental, refletida em comportamentos utilitaristas, próprios de uma sociedade que se organiza de maneira insustentável. Enfrentar tais problemas, sob o ponto de vista da autora, implica na construção de uma crítica profunda a todo um modelo de civilização, pois o privilégio dado a soluções técnicas consolida a alienação. Como consequência, leva à crença equivocada de que a produção do lixo é algo natural, que seus problemas afetam a todos indistintamente e, que a sua correta manipulação viabiliza a reprodução dos padrões atuais de organização social.

Contudo, observou-se que sete alunos responderam que a EA não é realizada, dentre os quais a maioria ressaltou que isto se deve em grande parte pela falta de conhecimento por parte dos próprios alunos e professores.

Além disso, quando os alunos foram questionados sobre as disciplinas que trabalham com EA foi observado algo que é muito recorrente no âmbito educacional, a resposta de que o assunto é abordado, apenas, nas aulas de Ciências. Somente dois alunos relacionaram a EA com outras disciplinas além dessa, respondendo que é também vista nas aulas de Geografia e Português.

Apesar de a interdisciplinaridade ser discutida em diversas pesquisas no campo da Educação, muitos professores tendem a interpretá-la como uma 
justaposição das disciplinas, o que na verdade deve ser considerado um trabalho multidisciplinar que não apresenta uma relação aparente entre si.

Para Philippi e Neto (2011, p. 36), citando Piaget:

A multidisciplinaridade, trata-se do "patamar inferior" de interação que ocorre quando a solução de um dado problema requer a colaboração mútua de duas ou mais ciências, ou setores do conhecimento, mas sem que para isso as disciplinas contribuintes sejam modificadas ou enriquecidas. Não se trata, portanto, de interações propriamente ditas, mas tão somente da aquisição, por exemplo, por grupos de pesquisadores, de um nível de informação mútua.

Conforme os PCN (1997) a interdisciplinaridade questiona a segmentação entre os diferentes campos de conhecimento, produzida por uma abordagem que não leva em conta a inter-relação e a influência entre eles e questiona a visão compartimentada (disciplinar) da realidade sobre a qual a escola, tal como é conhecida, historicamente se constituiu. Refere-se, portanto, à uma relação entre disciplinas.

De acordo com Pombo (2004), a questão é reconhecer que determinadas investigações precisam de abertura para conhecimentos que pertencem, tradicionalmente, ao domínio de outras disciplinas. Por este motivo, só essa abertura permitirá a compreensão das camadas mais profundas da realidade que se quer estudar.

Deste modo, a interdisciplinaridade visa interligar os diversos saberes, sem descaracterizar suas particularidades. Assim,

\begin{abstract}
Para que ocorra a interdisciplinaridade não se trata de eliminar as disciplinas, trata-se de torná-las comunicativas entre si, concebê-las como processos históricos e culturais, e sim torná-la necessária a atualização quando se refere às práticas do processo de ensino-aprendizagem (FORTES, 2009, p. 4).
\end{abstract}

Contudo, instituir novas propostas no sentido interdisciplinar, é um trabalho árduo, principalmente se consideradas as inúmeras características tradicionais que ainda permeiam nossa práxis educativa e, consequentemente, processos de ensino-aprendizagem. Neste sentido, Thiesen (2008, p. 545) aponta que:

Não é difícil identificar as razões dessas limitações; basta que verifiquemos o modelo disciplinar e desconectado de formação presente nas universidades, lembrar da forma fragmentária como estão estruturados os currículos escolares, a lógica funcional e racionalista que o poder público e a iniciativa privada utilizam para organizar seus quadros de pessoal técnico e docente, a resistência dos educadores quando questionados sobre os limites, a importância e a relevância de sua disciplina e, finalmente, as exigências de alguns setores da sociedade que insistem num saber cada vez mais utilitário.

Dessa forma, a tendência de fragmentar para compreender, por séculos vem dividindo as diferentes vertentes do conhecimento, dissociando aspectos essenciais para a formação dos saberes que as discussões acerca da interdisciplinaridade possibilitou repensar, ideias antes estagnadas e limitadas devido a unilateralidade do conhecimento agora estão sendo levadas para os diversos debates sobre esse processo educativo que requer os diferentes campos do conhecimento para o seu desenvolvimento. 
Porém, apesar das inúmeras publicações acadêmicas e sua contemplação em documentos oficiais, o que podemos observar, como defendido por Pombo (2005, p. 5) é que a interdisciplinaridade está sendo descaracterizada de seu sentido original, prevalecendo a compartimentalização de saberes, sendo utilizada para reorganizar disciplinas e pô-las lado a lado, sendo mais uma palavra pomposa nos discursos: "e esta utilização excessiva gasta a palavra, esvazia-a, tira-lhe o sentido". Contudo,

\begin{abstract}
A escola, como lugar legítimo de aprendizagem, produção e reconstrução de conhecimento, cada vez mais precisará acompanhar as transformações da ciência contemporânea, adotar e simultaneamente apoiar as exigências interdisciplinares que hoje participam da construção de novos conhecimentos (THIESEN, 2008, p. 550).
\end{abstract}

Essa maneira de encaminhar o trabalho, buscando uma integração entre os conteúdos das diferentes disciplinas, é um passo importante, pois possibilita uma reflexão mais contextualizada sobre as questões ambientais. No entanto, tal encaminhamento da prática escolar leva a um trabalho individual do docente, não havendo uma real interação entre os professores, os alunos e a comunidade escolar.

Ao serem questionados a respeito da importância que as ações na área de EA representam, todos os alunos responderam achar importante, podendo ser enfatizadas as respostas de alguns:

"Sim, para um mundo melhor e uma escola mais limpa". (Aluno C)

"Sim, se continuar assim nosso planeta não vai aguentar". (Aluno D)

"Sim. Para a gente cuidar o meio ambiente e a natureza onde vivemos". (Aluno E)

Essas justificativas demonstraram a compreensão sobre a importância da EA, mas ainda possuem uma visão bastante reducionista. Isso porque, é desprovida de um entendimento de que o posicionamento de cada um tem seu valor para a formação de um cidadão atuante na sociedade.

Percebeu-se, então, nesses discursos, a relevância da inserção da EA no âmbito escolar, apostando no uso desse espaço para práticas socioambientais que possam favorecer a sensibilização em relação ao local com a participação efetiva dos alunos, professores e de toda a comunidade. Assim buscar-se-á, nessas práticas, o diálogo, valorizando mais o escutar e o aprender com o outro; encontrando nesses diálogos outros sujeitos, que compartilhem intencionalidades e, na cumplicidade dessas intenções, busquem trabalhar, coletivamente, em prol de um bem comum.

\title{
CONSIDERAÇÕES FINAIS
}

Diante das análises realizadas nesta investigação, conclui-se que a maioria dos alunos do 60 ano apresentou uma visão conservacionista de EA. Essa concepção mostra-se simplista, uma vez que a EA foi compreendida de forma dissociada, sendo apenas um caminho para cuidar da natureza.

Verificou-se que a EA, é abordada, predominantemente, nas aulas de Ciências e, em menor proporção, em aulas de outras disciplinas, como Geografia e 
Português, considerando-se a existência de uma sutil iniciativa de multidisciplinaridade e não da interdisciplinaridade.

Esse caráter multidisciplinar é reforçado quando os professores de Ciências, Geografia ou Português, por exemplo, abordam em suas aulas conceitos e teorias diferentes relacionados apenas a sua respectiva área de conhecimento. Ou seja, não existe uma relação mútua para atender a natureza múltipla dessa questão com maior complexidade.

Portanto, observa-se a necessidade da apresentação de critérios para a construção e desenvolvimento coletivo dessas propostas para que ocorra de forma participativa entre as diferentes áreas do conhecimento, trocas de saberes e integração, não apenas uma justaposição de disciplinas diversas, que, na maioria, das vezes não apresentam relação aparente entre si de forma continuada.

Contudo, verificou-se que existe uma abertura de toda comunidade escolar para que práticas socioambientais sejam desenvolvidas nesse espaço e possibilitem o envolvimento dos professores num contexto interdisciplinar, promovendo um avanço no desenvolvimento das propostas de Educação Ambiental.

\section{AGRADECIMENTOS}

Agradecemos à Fundação Araucária pelo apoio dado ao trabalho desenvolvido. 


\title{
Environmental education in the context of basic education
}

\begin{abstract}
Environmental crisis created by the various human actions combined with the lack of knowledge about this subject has been the subject of several discussions since the 1960s and 1970s, when it ceased to be a subject of environmental groups and became part of the agenda of various sectors of the Society, including schools. By having its origins in struggles and achievements in outside educational spheres groups, this discussion has advanced fragile way with regard to theoretical and methodological issues, and limitations of Environmental Education and its educational processes can be observed to date. In the current context it is necessary that EE is addressed in schools in a perspective that seeks to break away from reductionist, timely and pragmatic practices that aim only to separate waste, plant trees and conserve natural resources. more needs to be done in discussions that lead to our students to understand a more critical and transformative Environmental Education. In view of this, the study aimed to investigate the conceptual knowledge about Environmental Education of 22 students of sixth grade of Elementary School, from a State College of Dois Vizinhos town, Southwest of the State of Paraná, through the application of questionnaires and socioenvironmental experiences. For that, questions were asked about concepts related to Environmental Education and, later, practices were carried out on an ecological trail that is close to the college. Afterwards, these data were analyzed in a qualitative way, revealing a conservationist view on Environmental Education by most of the students (13), who were later worked through workshops carried out by students linked to PIBID/BIOLOGIA.
\end{abstract}

KEYWORDS: Environmental education. Basic education. Educational processes. 


\section{REFERÊNCIAS}

AMARAL, A.Q. Educação Ambiental e a dimensão política: um estudo de caso do Programa de Formação de Educadores Ambientais da Usina Hidroelétrica de Itaipu Binacional. Tese Doutorado. Programa de Pós- Graduação, Unesp Rio Claro. 2018.

BAUMAN, Z. Vida para consumo: a transformação das pessoas em mercadorias. Tradução de Carlos Alberto Medeiros. Rio de Janeiro: Jorge Zahar, 2008.

BORNHEIM, G. A Temática Ambiental na Sociedade Contemporânea. Educação: Teoria e Prática, Rio Claro, v. 9, n. 16, p. 1 - 9, jan-jun, 2011, juldez2011.

BRUGGER, P. Educação ou adestramento ambiental? 2 ed. Florianópolis: Letras Contemporâneas, 1994.

CARNIATTO, I.; VALDAMERI, A.; AMARAL, A. Q. Nossas riquezas e seus riscos. Revista Diocesana Catedral, 2011.

CARVALHO, L. M. A Temática Ambiental e a Escola de 10 grau. 1989. 286f. Tese (Doutorado em Didática) - Faculdade de Educação, Universidade de São Paulo, São Paulo, 1989.

A temática ambiental e a formação de professores In: BICUDO, M. A. V.; SILVA JUNIOR, C. A. Formação do Educador - dever do estado, tarefa da universidade. São Paulo: UNESP, 1994.

Educação Ambiental e a Formação de Professores. In: BRASIL. OFICINA PANORAMA DE EDUCAÇÃO AMBIENTAL NO BRASIL, Brasília, 2000. Panorama da Educação Ambiental no Ensino Fundamental, v. 1, p. 55-64. Brasília: Ministério da Educação, 2000.

A Temática Ambiental e o Ensino de Biologia: compreender, valorizar e defender a vida. In: MARANDINO, M. et al. (Orgs.). Ensino de Biologia: conhecimentos e valores em disputa. Niterói: EDuff, 2005.

A temática ambiental e o processo educativo: dimensões e abordagens. In: CINQUETTI, H. S.; LOGAREZZI, A. Consumo e Resíduos - Fundamentos para o trabalho educativo. São Carlos: EDUFSCar, 2006. 
DEVECHI,C.P.V; TREVISAN, A.L. Sobre a proximidade do senso comum das pesquisas qualitativas em educação: positividade ou simples decadência?. Revista Brasileira de Educação, v. 15 n. 43, p. 148-201, jan./abr. 2010.

DENZIN, N; LINCOLN, Y. A disciplina e a prática da pesquisa qualitativa. 0 Planejamento da pesquisa qualitativa: teorias e abordagens. Porto Alegre: ArtMed, 2006.

FORTES, C.C. Interdisciplinaridade: origem, conceito e valor. Revista Acadêmica, 2009.

GIBBS, G. Análise de dados qualitativos. Tradução Roberto Cataldo Costa. Porto Alegre: Artmed, 2009.

LAYARGUES, P. O cinismo da reciclagem: o significado ideológico da reciclagem da lata de alumínio e suas implicações para a educação ambiental. In: LOUREIRO, F.; LAYARGUES, P.; CASTRO, R. (Orgs.) Educação ambiental: repensando o espaço da cidadania. São Paulo: Cortez, 2002.

LEFF, E. Saber ambiental: sustentabilidade, racionalidade, complexidade, poder. 7 ed. Petrópolis: Vozes, 2009.

MININNI-MEDINA, N. Breve histórico da educação ambiental. In: PADUA, S. M.; TABANEZ, M. F. Educação ambiental: caminhos trilhados no Brasil. Ipê: Instituto de pesquisas ecológicas. Brasília: 1997.

OLIVEIRA, A. L; OBARA, A. T.; RODRIGUES, M. A. Educação Ambiental: concepções e práticas de professores de ciências do ensino fundamental. Revista Eletrônica de Enseñanza de las Ciencias, v. 6, n. 3, p. 471-93, 2007.

PHILIPPI, JR, A. NETO, A.J.S. Interdisciplinaridade em ciência, tecnologia e inovação: Barueri, São Paulo, 2011.

POMBO, O. Interdisciplinaridade: ambições e limites. Lisboa: Relógio D’Água, 2004.

SANTANA, L. C. Educação Ambiental: de sua necessidade e possibilidades. In: International Workshop on Project Based, 2005. Guaratinguetá, PBL Tech 2005 International Workshop on Project Based - Learning and and New Technologie, p. 1-14, 2005. 
THIESEN,Juares da Silva. A Interdisciplinaridade Como Um Movimento Articulador No Processo Ensino-Aprendizagem. Revista Brasileira de Educação, v. 13 n. 39 set./dez. 2008.

Recebido: 2017-06-28

DOI: $10.3895 /$ rbect.v11n3.6068

Como citar: AMARAL, A. Q.; SILVA, M. A.; MIGUEL, K. S.; LIMA, D. M.; CUTCHMA, T. R. Educação Ambiental no contexto da Educação Básica. Revista Brasileira de Ensino de Ciência e Tecnologia, v. 11, n. 3, 2018. Disponível em:

<https://periodicos.utfpr.edu.br/rbect/article/view/6068>. Acesso em: xxx.

Correspondência: Anelize Queiroz Amaral - any_qa@hotmail.com

Direito autoral: Este artigo está licenciado sob os termos da Licença Creative Commons-Atribuição 4.0 Internacional.

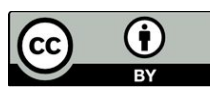

